\title{
Rossetti Filippo
}

TSRM presso U.O.C. Medicina Nucleare, Azienda Ospedaliera di Rilievo Nazionale e di Alta Specialità "San Giuseppe Moscati", Avellino

KEYWORDS: Health Care Professions Management, action strategies, business organization, SSN, health care professions, ABC method,

\section{ABSTRACT}

The Italian national health system, in addition to being a world-class excellence, over the years has become increasingly competitive and dynamic, pushing those who coordinate and manage to have to work alongside staff figures and the most suitable tools to face the most pressing needs and contingencies strategic and operational. For this reason, the National Health Plan (PSN), the Regional Health Plan (PSR) and the National Prevention Plan (PNP) have been identified as the main planning tools, which are the basis of health planning at all levels, from that National to regional and local. The figure of the Head of the Health Professions and, specifically, that of the technical-diagnostic area, in the context of complex health systems such as Healthcare Companies and Hospitals, is indispensable within the strategic staff and as a necessary figure for the implementation of the programming and coordination of activities. Moreover, it is essential to deal with the fundamental issues regarding processes and work cycles by building, on these bases, the concept and importance of the choice of the management system according to advanced skills and thanks to the possession of a strong managerial culture.

\section{INTRODUCTION}

The innovations introduced in recent years have initiated a process of reorganization of the management method that has led to the introduction of visions and tools to support the new information and decisionmaking needs. With the companyization, however, it has not gone from public management to purely private management, but has equipped itself with work tools typical of the private sector and previously unknown to the public administration. The important change that occurred with the process of corporatization of health facilities highlights the reference principles completely opposite to the previous organization, namely:

- Principle of autonomy of management bodies and autonomy of politics with respect to technology, returning to politics its fundamental function in terms of planning the direction and control in complete self-determination;

- Principle of cost-effectiveness of management, understood as the overall economic-financial balance of the healthcare company. No more bureaucratic management, attentive only to the formality of the acts, but an organization aimed at objectives and results with allocation and use of resources to stimulate competitiveness and therefore the efficiency of the structures;

- Principle of the responsibility of those who manage, in the sense of managerial responsibility based on the evaluation of the results achieved with respect to the objectives previously set.

Precisely due to the gradual affirmation of these principles, the world of public health in Italy has increasingly come into alignment with corporate standards, especially in the face of expenditure regulation by bodies and ministries who have wanted to start keeping the results strictly under control. management. The further objective was to introduce competitive mechanisms in the health system where competitiveness was aimed at improving performance in terms of effectiveness (ability of the company or one of its operating units to achieve the set objectives), efficiency (relationship between resources employed and services provided or a more rational use of the resources assigned to achieve the set objective) and quality of services to ensure an economic / managerial control methodology based on the number of services. In the 90s, moreover, a real revolution began for the professional qualification of health workers that was born almost simultaneously, but not dependent on the reorganization and optimization process of the health management. Between 1994 and 1999 for each healthcare profession, with a specific ministerial decree, the relative professional profile is issued which frames the professional figure in a general way, establishes their specific skills and field of activity. The real turning point, however, occurs with the approval of Law no. 42/1999 on "Provisions relating to health professions" which determines the abolition of the auxiliary character, the recognition of autonomy, the repeal (for the professions that had it) of qualification rules of a job description and then the strong reference to the field of activity and responsibility of the health professions which is determined by the relative professional profiles, by the didactic regulations of the respective degree courses and by the specific ethical codes. Shortly thereafter another law was issued, n. 251/2000 on "Discipline of the health professions, nursing, techniques, rehabilitation, prevention as well as the obstetric profession", with which access to 
management is recognized to the health professions, giving them a status worthy of the relevance they have over time earned in the field. Compared to the previous one, the legislation enters specifically with keywords such as "professional autonomy", "specific area of activity and responsibility", "ethical codes", "teaching regulations", "basic and post-basic training". It also establishes the methods for accessing the management, not yet fully implemented, but fundamental, as already mentioned, within the general business organization. On April 2, 2001, the Interministerial Decree was issued containing "Determination of the classes of university degrees of the health professions" with which the didactic regulations of the courses of health degrees (until then diplomas) relating to the Faculty of Medicine and Surgery of the universities were established Italians and classified the twenty-two existing health professions in health areas. On the same date, the Ministerial Decree was issued containing the "Determination of the classes of the specialized university degrees of the health professions" with which the specialized degree courses relating to the degree courses are established. The subdivision takes place according to the degree model with a grouping of four health areas, namely:

- class 1 , of specialist degrees in nursing and midwifery;

- class 2 , of specialist degrees in the sciences of the health professions of rehabilitation;

- class 3, of specialist degrees in the sciences of the technical health professions (technical-diagnostic area and technical-assistance area);

- class 4 , of specialist degrees in the sciences of the health professions of prevention.

METHODOLOGY AND MATERIALS Before explaining in depth the characteristics of managerial management and of the methodology applied for clinical governance, it is important to underline that the reforms made during the 90 s within the NHS led to substantial changes from a technical point of view, administrative and managerial, important changes regarding the relationship between who proposes and who benefits from the service. In fact, at the same time, the way of considering the patient has also changed, seen as a user interested above all in the quality of the services received rather than in the internal dynamics of the structure to which he is addressed. On the other hand, however, doctors and health professionals have all been called upon to adapt to the innovations that the government and

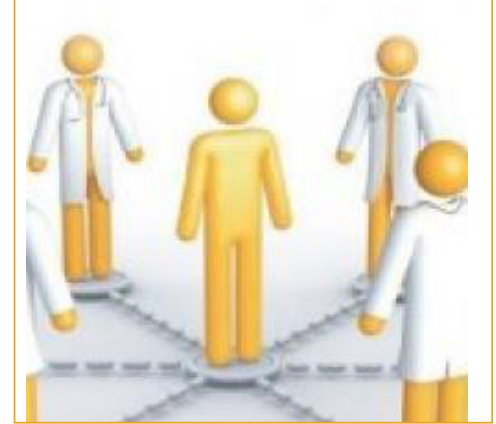

Fig. 1 - Patient at the center of care

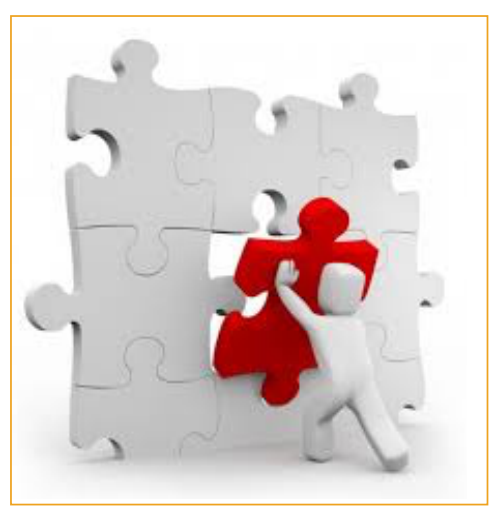

Fig. 2 - Taking "care" and the bio-psychosocial approach. the regions have introduced into the system, managing to exploit as much as possible the full potential, to pursue the continuous improvement of the activity by providing an ever closer response, from both a clinical and human point of view, to the expectations of those who need assistance and to enhance what research and new technologies have brought to light with reference to the quality of services. All this, as a consequence, has also led to a change in status by determining a health response of the "to care" type, or "assistance", through a bio-psycho-social approach to the user, typical of the area of health professions.

Returning to the strictly management point of view, the managers of the health professions and, specifically, of the technical-diagnostic ones, must therefore be able to play an important role in the transition towards a management by processes with responsibility for programming, management and coordination of personnel, updating of the same and analysis of the assistance services provided. Adequate attention must also be given to interpersonal skills because professional management must be able to motivate other operators to give their best in order to achieve common and relevant goals both for the people directly concerned and for the whole company. It is clear that in the face of the regulatory and professional framework, the scenarios that open up for the health professions in the imminent future are potentially broad but to be evaluated with extreme attention and prudence given the complexity of the matter and the large number of professionals involved. The manager of the technical-diagnostic area, in the specific organization, is based on three different organizational functions, namely Planning, Management and Evaluation. Planning can include:

- $\quad$ assist the Director of the department in defining the budget objectives;

- $\quad$ promote the definition of homogeneous diagnostic procedures;

- detect the training needs of personnel relating to the diagnostic area;

- define paths for the guided insertion of new hires.

The following are part of the Management:

- $\quad$ promote meetings and meetings between technicians aimed at implementing the activities proposed by the department;

- manage staff mobility;

- $\quad$ promote the application of guidelines to define workloads;

- identify reward systems and personnel motivation systems.

- Finally, Evaluation activities are:

- evaluate the proposals of the coordinators of operational units on the use of resources;

- participate in the definition of the criteria for the choice of diagnostic equipment.

In this regard, it is important to know how to instill in one's employees the desire and discipline for which teamwork, coordinated and serene, can help in achieving the common goal and mission of the organization. What can help the manager to achieve the goals set by superiors and the company organization is time management; parameter which, if used correctly, allows to achieve the results in the best possible way. According to Vilfredo Pareto, an economist and sociologist of the 19th century, in fact, $80 \%$ of the time spent on $20 \%$ of the important and strategic problems that give 
$80 \%$ of the results is more productive than using $20 \%$ of the time spent on $80 \%$ of the unimportant and operational problems that give $20 \%$ of the results. Time, in particular, must be used to exploit and work on the executive's four macro activities: planning, organization, management and control. The planning concerns the determination of the purposes of the structure, the design of action plans, the collection of information and the elaboration of scenarios and the planning of the development of new services, all based on the comparison with competitors and on any strategies to be imported. Within the organization, the necessary and available resources are assessed, working times are planned, tasks are divided, responsibilities are assigned and work is done to improve production processes and quality. As far as management is concerned, the exploitation of tools such as delegation, the development of one's staff, rewards and attention to the internal climate is fundamental here since this phase, delicate and fundamental at the same time in the management of the organization, is the one that it leverages people and ways of doing and acting; features that, if properly enhanced, as mentioned above, help to better achieve the mission and the final results of the organization. Finally, there is the control phase that works on the evaluation and definition of performance standards, on the monitoring of workflows and on the data collection of trends and performances. In all this complex management system relating to the role of the manager or manager, what is most important is knowing how to discriminate priorities and discriminate what is necessary, that is, which affects the fundamental objectives, from what is urgent, i.e. managed within a certain deadline to avoid damage, and from what is not urgent; these are priorities which, if established incorrectly, risk undermining the manager's own work and, consequently, the serenity of the group and of work in general. In this regard, it may be important to rely on the $\mathrm{ABC}$ system for which tasks A must be carried out immediately because they have serious consequences if neglected, tasks B should be carried out immediately and not neglected excessively so as not to turn into tasks A, tasks C, finally, are the ones that can be postponed. The purpose of this whole system is the planning of the time upstream to decide what are the tasks, the objectives and the importance, the scheduling of time to decide the sequence and temporal duration of the tasks and the organization of time, i.e. being able to take advantage of the resources to work correctly on the objectives chosen from time to time in the time established for each operation.

\section{RESULTS AND DISCUSSION}

It is clear that the variability of the internal and external context of the company is able to strongly influence the organization and the need to adopt some particular forms of work and coordination (perhaps proved inefficient in other contexts) and not others (which proved to be very efficient. in other types of contexts but which do not work in the present context). The corporate organizational structure must always take into account the consistency of the variables and organizational elements, first of all with each other, and subsequently with the environmental situation within the organization and outside the environment; for this reason, it cannot be ignored that the choices in organizational terms strongly depend on the internal situation existing in the company or in an operating unit and on the external environment in which the same structure operates and within which they take place all processes. Recalling what has already been described above, the delegation performs an essential function for the fulfillment of the tasks of the working group since, based on the type of authority that one wants to exercise and thanks to the praise and stimulation of the staff, it is possible to achieve better and more efficient management results managing to be, at the same time, a responsible decision maker, diffuser, manager and coach and relying on the values, attitudes, motivation of the staff, characteristics that are more difficult to modify if not with emotional intelligence, empathy and ability to adapt and be persuasive, qualities that make a manager an excellent leader and that best describe the role and functions of a responsible manager. Although in recent times the general working conditions have worsened, the human and relational working conditions have managed to find a square between them; this allows managers to be able and able to manage in a better way the difficulties that are encountered every day such as the coexistence of different generations of workers in the same environment and the correct exploitation of the potential of each employee.

\section{Acknowledgments}

The article is based on the author's master's thesis. Some parts of the thesis and, consequently, of the text, are objective and, therefore, taken from documents and deeds cited in the bibliography. Most of the text results from an elaboration of the author's intellectual property.

\section{REFERENCES}

1. Law 42/1999, February 26;

2. Law $251 / 2000$, n. 251 ;

3. Ministerial Decrees 2 April 2001;

4. Triassi M. (2011). Management in healthcare. The governance of complex health systems. Universe Publishing Company;

5. is. Alvaro, R., Antonetti, G., Petrangeli, M., Guerrieri Wolf, M. (2011). The Manager of the Health Professions. Role and perspectives in the context of public administration. Edises;

6. Antonetti, G., Alvaro, R., Bonelli, J., Scampati, P., De Vincenzo, L., Mattei, M., Farfusola, P. (2019). The leadership of the health professions. Role, perspectives and critical issues in the light of current legislation. Universitalia;

7. Rotondi, M. (2019). The management of Human Resources in Healthcare. Intervention strategies for Health Authorities. Franco Angeli s.r.l. Milan. 